\title{
Una cosa extraña o la extrañeza de las cosas. Acerca de Die Sorge des Hausvaters de Franz Kafka
}

\author{
Anna MONTANÉ ForAsté \\ Universitat de Barcelona \\ amontane@ub.edu
}

Recibido: 9 de diciembre de 2010

Aceptado: 9 de febrero de 2011

\section{RESUMEN}

Odradek, la extraña criatura que Kafka dio a conocer con su breve narración Die Sorge des Hausvaters (1919), sigue siendo para el lector un desafío intelectual y emocional. El artículo presenta un recorrido por la historia de la interpretación de este texto que es a su vez reflejo de una actitud cambiante ante lo extraño. Odradek ha dejado de ser la figura inclasificable cuya otredad urge anular para, a la luz de las aproximaciones más recientes desde el ámbito de la Kulturwissenschaft, convertirse en icono de la insuperable extrañeza del mundo de las cosas con la que los humanos nos vemos confrontados.

Palabras clave: Odradek, interpretación, Kulturwissenschaft.

\section{A Strange Thing or, the Strangeness of Things: Concerning Franz Kafka's Die Sorge des Hausvaters}

\begin{abstract}
Odradek, the strange creature Kafka made universally known through his short story Die Sorge des Hausvaters (1919), continues to pose a strong intellectual and emotional challenge for readers. This paper presents an overview of the history of interpretation surrounding this text, which, at the same time, reflects how attitudes towards Otherness have changed through history. As shown by the most recent approaches from Kulturwissenschaft, Odradek no longer stands for the unclassifiable creature whose Otherness must be suppressed, but has become an icon of the insurmountable strangeness of the world of things human beings are confronted with.
\end{abstract}

Keywords: Odradek, Interpretation, Kulturwissenschaft.

SUMARIO: 1 . Un enigma de largo alcance. 2. Odradek no es tan extraño. 3. Odradek y el Hausvater. 4. Odradek y la extrañeza de las cosas. 5. Conclusión 


\section{Un enigma de largo alcance}

Con Odradek ${ }^{1}$, Franz Kafka creó un enigma que había de tener largo alcance. Ya en su momento pasó a formar parte del elenco de criaturas extrañas que Borges reunió en el Libro de los seres imaginarios, donde esta suerte de carrete de hilo o simple trozo de madera que no parece haber tenido jamás una utilidad, que tan pronto se instala en el desván como en las escaleras de la casa y que, si quiere, habla y se ríe, comparte protagonismo con híbridos mitológicos como la Esfinge que desolaba Tebas. Al lado del monstruo griego el diminuto Odradek tendría que dar risa y, no obstante, cuentan que el primero fue vencido y se precipitó de lo alto de la montaña mientras que la invención de Kafka sigue dando quebraderos de cabeza. Al desafío intelectual y emocional que es Odradek sin duda contribuye el que Kafka lo ubicara en uno de sus ámbitos predilectos, en el espacio de lo cotidiano y supuestamente conocido: en casa. Kafka confronta con Odradek a un padre de familia y éste es puesto a prueba; en el día a día irrumpe un ser inclasificable y ello es causa de preocupación. Lógicamente, tratándose de un texto de Kafka, el hecho de que lo familiar (o incluso doméstico) esté representado por una figura paterna despierta suspicacias -si rápidamente se asocia el padre con una imagen del poder, un padre preocupado huele a trampa-, sin embargo y a pesar de que la preocupación del padre tiene, en efecto, su doblez, quisiera resaltar que difícilmente hallaríamos un cabeza de familia al que Odradek no causara inquietud. A modo de ejemplo, recuerdo lo que muy al comienzo de Der Nachsommer de Stifter Heinrich cuenta de su padre. Éste, dice, no podía soportar las habitaciones mixtas (como sería un dormitorio que a la vez fuera sala de juegos) y no por una manía circunscrita a la esfera de lo doméstico, sino por una cuestión de principios: "Jedes Ding oder jeder Mensch, pflegte er [der Vater] zu sagen, könne nur eines sein, dieses aber muß er ganz sein" (Stifter [1857] 2005: 8). El padre evoca claras líneas divisorias, una idea estilizada de orden que posibilita una convivencia apacible y que, quien más, quien menos ha interiorizado o ritualizado: cada cosa en su sitio y un sitio para cada cosa. No es difícil imaginar, pues, que el híbrido Odradek habría sido una pesadilla para el padre de Heinrich o, como mínimo, justificado motivo de preocupación.

\section{Odradek no es tan extraño}

El historial de las interpretaciones de las que ha sido objeto el texto de $\mathrm{Kafka}^{2}$ da fe, en cambio, de que la preocupación del padre que se enuncia en el título -die Sorge des Hausvaters - fue durante largo tiempo ignorada. Muchos fueron los que

${ }^{1}$ Die Sorge des Hausvaters se publicó por primera vez en 1919 en Ein Landarzt. Kleine Erzählungen. Harmut Binder sitúa su redacción hacia finales de abril de 1917 (BINDER 1977: 230-233).

${ }^{2}$ Sobre el lugar prominente que según la opinión de destacados expertos en la obra de Kafka Die Sorge des Hausvaters ocupa dentro de la producción del escritor praguense (STAHL 1966: 68). 
pusieron todo su empeño en dilucidar qué cosa o quién era Odradek olvidando así que la narración de Kafka justamente presenta el intento de resolver el enigma Odradek como un problema ${ }^{3}$, que nadie sabe quién es Odradek: las investigaciones etimológicas fracasan, la atención a su semblante sirve de bien poco y la vía comunicativa ofrece escasa luz. Ante la inseguridad que emana el texto los exégetas reaccionaron con propuestas firmes de corte alegórico que, sin embargo, no logran alejar de sí la sospecha de la arbitrariedad. Desgajada del movimiento que traza la narración, o sólo escogiendo algunos de sus detalles, la incógnita Odradek se ha resuelto, enumero sólo un par de ejemplos, por la vía religiosa -Odradek es el cristianismo que deriva del judaísmo-, por la marxista -Odradek es la imagen de alienación- o acudiendo a la biografía del autor: Odradek sería el propio Kafka o la obra que él nunca consigue escribir o la obra ya escrita que le causa disgusto ${ }^{4}$. Común a estas lecturas es el notable esfuerzo realizado para neutralizar la perplejidad que genera Odradek y, en este sentido, documentan una necesidad o impulso por parte de los comentaristas de convertir rápidamente lo extraño en conocido. Por otra parte, esta reacción ante el enigmático Odradek es equiparable a posiciones como la que representa Peter-André Alt, cuando dice que todo el esfuerzo analítico podría haber sido ahorrado de ponerse más atención al decidido veto a la interpretación que el texto de Kafka formula desde el comienzo: Odradek ya ha sido objeto de discusiones etimológicas tan eruditas como infructuosas. Para este biógrafo de Kafka, Odradek es pura forma que nada significa (Alt 2005: 511-513) y Die Sorge prefiguraría el destino de todos los textos de Kafka, formas precisas carentes de un sentido unívoco que encienden acaloradas discusiones: "Der Odradek-Text eröffnet folglich keinen metaphysischen Horizont, sondern nur eine klar umrissene Struktur, der die Ebene der Referenz fehlt (es sei denn, man verstünde darunter die Selbstrepräsentation der Literatur)" (Alt 2005: 513). Por activa-Odradek tiene un significado-o por pasiva-Odradek es pura forma sin referente-, la rareza de Odradek se ha visto transformada en algo

${ }^{3}$ En palabras de Günter Saße: "[D]er Text selbst [hat] einen Verstehensprozeß zum fast ausschließlichen Inhalt" (SABE 1978: 263).

${ }^{4}$ En su día Heinz Hillmann sistematizó y ordenó por tipologías todas las interpretaciones de las que había sido objeto Die Sorge (HiLlmann 1967: 197-210). Por mi parte me he limitado a subsumir una actitud interpretativa que busca despejar incógnitas estableciendo claras correspondencias bajo el comparativamente mucho más inexacto marbete de "interpretaciones de corte alegórico" porque mi interés aquí no son los comentarios en su detalle, sino su tendencia. Asimismo tampoco es mi intención negar el trasfondo biográfico de Die Sorge que, por otra parte, está sólidamente documentado (p. e. HillmanN 1966, Binder 1977, Alt 2005). Y aunque a estas alturas no es preciso extenderse sobre la insuficiencia de una aproximación meramente biográfica quizás no sea superfluo traer a colación un detalle que ilustra una vez más que la verdad de la literatura no se agota en lo referencial, a saber: Es muy probable que Kafka tomara el nombre de Odradek de una marca de motocicletas que circulaban por Praga en tiempos de nuestro autor, un tío suyo tenía una en propiedad y el mismo Kafka la había conducido (WAGENBACH 1985: 47) pero, a pesar de esta evidencia, hasta la fecha no han cesado las propuestas de nuevas etimologías para el nombre de Odradek como camino de exploración del sentido del texto de Kafka. Al respecto vid. EHRICH-HAEFELI (1990), MiLNER (2004). 
conocido o en nada (que conocer), haciéndose caso omiso al perspectivismo ${ }^{5}$ de la narración de Kafka, a que entre Odradek y nosotros está el padre de familia

\section{Odradek y el Hausvater}

El reconocimiento de la relevancia del padre en la historia de Odradek no se produjo hasta que los intérpretes dejaron de centrarse en el aspecto de esta invención para fijarse en el aspecto del texto mismo ${ }^{6}$. Este desplazamiento permite ver que, ya desde el título, Odradek es presentado como una experiencia del padre y que, como en su día señaló Hillmann, los cinco párrafos que siguen -cinco vías de aproximación a Odradek- no muestran una evolución de Odradek, sino una evolución en la descripción de Odradek (Hillmann 1968: 200) y ninguna otra voz acude a completar o a corregir el discurso del padre; Die Sorge se revela así como un ejemplar puro de la tan citada univocidad de la perspectiva característica de los textos de $\mathrm{Kafka}^{7}$, lo cual, en un sentido estricto, no significa que la narración transporte íntegramente la conciencia del personaje, sino que escenifica el despliegue de esta conciencia guardando una distancia muy sutil, casi imperceptible, pero suficiente para que se pongan de manifiesto las contradicciones y cegueras del protagonista (Ehrich-Haefeli 1990: 248). Quien no atiende a esta diferencia, el lector identificado ${ }^{8}$, hace causa común con el padre y, como éste, acaba frustrado, es el caso de Stahl cuando dice que Odradek sería "Zeuge und Beweis einer unheilvollen, weil ergebnislosen Suche" (Stahl 1966: 75). El lector menos identificado tampoco llega a resolver el enigma Odradek pero, al menos, aprende a conocer al padre. Citando de nuevo a Hillmann: "Am Objekt wird klar, was das Subjekt ist” (Hillmann 1968: 201). Hillmann pone especial énfasis en la importancia que el padre de familia concede a la categorización exacta, en que la composición narrativa tan estricta es prácticamente un informe científico y, atento a la sintaxis de la narración -el sujeto de los cuatro primeros párrafos es el pronombre impersonal man y solo en el quinto y último párrafo aparece el personal de primera personadeduce que la actitud del "unberührbar kühler Beobachter" (Hillmann 1968: 202) que el padre mantiene mientras el objeto de investigación son el pasado y el presente de Odradek se hace insostenible cuando la pregunta es por el futuro porque, de repente, aparece la muerte como posibilidad y ello tocaría tan de cerca al padre

5 “Über das Wesen des Odradek [ist] nichts auszumachen ohne die Berücksichtigung des Subjektiv-Perspektivischen seiner Existenz" (STAHL 1966: 69).

${ }^{6}$ Esto no sucede hasta bien entrados los años sesenta del siglo pasado con el trabajo de STAHL (1966) y el imprescindible estudio de HiLLMANN (1968).

${ }^{7}$ Formulada por Friedrich BEIBNER en su celebérrimo estudio Kafka der Dichter (1958).

${ }^{8}$ Stahl ofrece un ejemplo de una lectura excesivamente literal del hallazgo de Beißner: "Er [Kafka] bemüht sich im Gegenteil immer das Rätselhafte durch die Verengung der Erzählperspektive in seiner Rätselhaftigkeit zu erhalten und bürdet dadurch dem Leser nicht nur das Rätsel, sondern noch die ganze unsägliche, in der Dichtung mitgestaltete Mühe um dessen Lösung auf' (STAHL 1966: 73). 
que el yo con sus sentimientos y afectos ya no podría ocultarse. De la curiosidad científica se pasa a la preocupación personal (Sorge $)^{9}$.

Aunque en líneas generales esta evolución es indiscutible, tal vez quepa una aproximación algo más acorde con la narración de Kafka entendida como dramaturgia o teatro del yo. En mi opinión, el narrador está desplegando ante nosotros una preocupación inherente a su condición de padre de familia: su Fürsorge o cuidado por el bienestar de los suyos a los que ahora parece que se ha añadido el tal Odradek ${ }^{10}$ y en el momento en que esta preocupación por el otro se presenta más intensa afloran las dimensiones de su preocupación personal (su Sorge). En este camino que iría de la Fürsorge a la Sorge la supuesta actitud científica forma parte de una estrategia de disimulo o de autoengaño que el texto, en la medida que lo permite su brevedad, deja entrever. Pequeños detalles muestran que el padre no hace todo lo que estaría en su mano por conocer a Odradek y que, de hecho, no le estaría mal deshacerse de su incómoda presencia (Ehrich-Haefeli 1990: 248).

Odradek es primero un nombre extraño sobre cuya etimología los expertos especulan sin éxito. Dejando ahora aparte el dudoso implícito de que dilucidar el origen del nombre de la cosa aporte luz sobre la misma, la lectura retrospectiva muestra que el padre conoce el nombre de Odradek porque esta cosa extraña habla, sin embargo, no es al portador del nombre a quien se pregunta por sus raíces, sino que para el esclarecimiento de Odradek se ha priorizado la implicación de la comunidad científica. El recurso a los filólogos, se encarga de puntualizar el padre, no es mero gusto por la entelequia, sino la consecuencia natural del encuentro con un ser que realmente existe: "Natürlich würde sich niemand mit solchen Studien beschäftigen, wenn es nicht wirklich ein Wesen gäbe, das Odradek heißt" (Kafka 2002: 282-284) ${ }^{11}$. Con esta exposición el padre consigue varias cosas. Presentarse como alguien que no escatima esfuerzos por dar con el sentido de Odradek, anticipar que la investigación será infructuosa y cubrirse las espaldas -si la ciencia no consigue saber qué cosa es Odradek parece lógico que tampoco lo consiga un padre de familia- y, por último, ganar para el discurso sucesivo el aura de cientificidad o de objetividad a la que colabora el mantenimiento del impersonal man. Sin embargo, en los dos párrafos siguientes, en los que Odradek aparece primero como una cosa inmóvil y después como algo que puede moverse, el padre

9 "[S]chon das Wort ,Sorge" weist darauf hin, daß der Hausvater nicht aus wissenschaftticher Neugier, sondern aus persönlicher Betroffenheit auf Odradek reagiert” (SABE 1978: 275).

${ }^{10}$ Creo que esta dimensión viene sugerida ya desde el título que no reza "Die Sorge des Vaters", sino que recoge el elemento Haus recuperado después en el texto con "unser Haus" como el espacio familiar: el de los hijos y nietos ("meine Kinder und die Kinder meines Kinders"). Ehrich-Haefeli señala que el Hausvater de Die Sorge no es la típica figura paterna de los textos de Kafka: "[D]ieser Vater ist durchaus bemüht, sich vernünftig und folgerichtig zu verhalten" (EHRICH- HAEFELI 1990: 243). Saße habla de un padre-soberano, centro de una estructura patriarcal frecuente en la obra de Kafka y en especial en Brief an den Vater (crf. SABE 1978: 271). En su día Brecht vio en el padre de Die Sorge un Hausbesorger pequeñoburgués que halla su merecido (SABE 1978: 270).

${ }^{11}$ En adelante, dada la brevedad del texto, las citas de "Die Sorge des Hausvaters" irán simplemente en comillas sin aludir a la página. 
ya no parece plenamente dispuesto a soportar la abertura de lo desconocido. Aunque su discurso es cauteloso, lleno de relativizaciones y suposiciones, discretamente va intentando domesticar la extrañeza de Odradek. "Es sieht zunächst aus wie eine flache sternartige Zwirnspule", dice el padre, pero al cabo de tres líneas el parecer se ha convertido en ser: "Es ist aber nicht nur eine Spule". Al final del segundo párrafo, Odradek es un carrete de hilo en forma de estrella que se puede mantener como erguido ("wie auf zwei Beinen aufrecht stehen") y, al final del tercero, se nos comunica su extraordinaria movilidad, atributo éste que el padre anuncia como quien no quiere la cosa (y cabe aquí tomar esta expresión en el nivel más literal): "Nähreres läßt sich übrigens nicht darüber sagen, da Odradek außerordentlich beweglich und nicht zu fangen ist". La movilidad de Odradek tiene varias caras y todas ellas apuntan sutilmente a una actitud de rechazo por parte del padre. En primer lugar, justo cuando Odradek ha sido descrito con un detalle notable se nos dice que su movilidad impide que la descripción devenga más precisa, que un mayor conocimiento requeriría atrapar a Odradek y aunque no es improbable que tomar a Odradek en las manos podría aportar más información sobre él, no está nada claro que el verbo más adecuado para expresar esta idea sea el verbo fangen $^{12}$. En segundo lugar, este padre que no puede atrapar a Odradek abriga la esperanza de al menos perderlo de vista, algo que se lee en la frase: "doch kehrt er dann unweigerlich in unser Haus zurück" y en tercer lugar, lo que es un ejemplo de la naturaleza huidiza de Odradek -los diversos espacios que ocupa- bien puede significar lo contrario: Odradek es una presencia insistente. A excepción del desván, los otros espacios que se mencionan -caja de escalera, pasillos, vestíbulo, barandilla de la escalera- son espacios de paso, espacios inevitables, de modo que precisamente la movilidad de Odradek podría propiciar su conocimiento, porque Odradek siempre sale al encuentro ${ }^{13}$. Paradigmática es en este sentido la escena que se esboza en el cuarto párrafo. El padre sale de casa, Odradek está apoyado en la barandilla y no son las prisas del movido Odradek lo que impide que el encuentro avance en la línea del supuestamente deseado conocimiento del otro, sino más bien la cerrazón del padre que de antemano reduce la conversación con Odradek a un ritual paternalista ${ }^{14}$. Obviamente, dice el padre, hay que tratar a Odradek como a un niño y no ponerlo en apuros: "Natürlich stellt man an ihn keine schwierigen

12 Sabido es que habitualmente el verbo fangen se aplica a animales (Tiere fangen) o a delincuentes (Verbrecher fangen).

${ }^{13}$ Los comentaristas suelen resaltar el no-lugar o zona marginal que ocupa Odradek (p. e. STAHL 1966, EHRICH-HAEFELI 1990). Walter Benjamin observó que los espacios que se mencionan en Die Sorge son los espacios predilectos de Kafka (BENJAmIN [1934] 1988). Si ello no fuera imitar el comportamiento del padre, tendería a pensar que este Odradek que el padre, sin ningún fundamento, imagina en las casas de otras familias se halla en el desván de su propia casa.

${ }^{14}$ En este caso, hablar de actitud paternalista, y no de actitud patriarcal, me parece más acertado, porque igual que el Hausvater se comporta, por ejemplo, el hijo Georg Bendemann con respecto a su amigo de San Petersburgo en Das Urteil. 
Fragen"15. El padre establece por adelantado los límites del diálogo reduciéndolo a un repertorio mínimo de preguntas fijas que no van más allá del nombre y el domicilio. Odradek tiene que decir ni más ni menos que lo que el padre necesita que diga, su decir no tiene que contradecir, por eso quizás quepa entender la risa de Odradek ${ }^{16}$ y más aun su silencio como una reacción a la actitud tan poco dialéctica del padre. Una suerte de animosidad subyace a este encuentro porque, por su parte, el padre también se desquita; justamente cuando Odradek aparece como alguien o algo capaz de comunicación, el padre lo presenta máximamente informe, como una cosa de la que nada se puede esperar: "oft ist er lange stumm, wie das Holz, das er zu sein scheint"17.

Con este Odradek prácticamente desrealizado, pura madera, el texto nos introduce en la final padre-Odradek. El padre pasa a la primera persona y se muestra más preocupado que nunca por Odradek: "Vergeblich frage ich mich, was mit ihm geschehen wird". La pregunta "qué ocurrirá con Odradek" (que bien podría continuar con un "cuando yo no esté") deriva en una consideración sobre la vida y la muerte que pone al descubierto la preocupación del padre por sí mismo, finalmente se manifiesta su Sorge y su dolor. El carrete de hilo andante aparece al padre como un ser que podría ser inmortal y esta posibilidad, aunque no se le confirme, le disgusta. En la hipotética supervivencia de Odradek está implícita la muerte del padre, pero más que su propia muerte lo que duele al padre es la perduración de Odradek (Hillmann 1967: 203), algo que se infiere de la plasticidad y concreción con las que el padre de familia se la hace presente; más que una idea, la inmortalidad de Odradek es ante todo una imagen: "Sollte er also einstmals etwa noch vor den Füßen meiner Kinder und Kindeskinder mit nachschleifendem Zwirnsfaden die Treppe hinunterkollern? Er schadet ja offenbar niemandem" ${ }^{\prime 18}$. El padre ve a Odradek dando tumbos ante sus nietos, proyecta con dolor una vida sin él, pero no es solo dolor lo que siente, también siente fastidio como indica la aparentemente superflua partícula auch en la frase: "aber die Vorstellung, daß er mich auch noch überleben sollte, ist mir eine fast schmerzliche". Implícitamente el padre expresa que Odradek no ha tenido bastante con importunarlo, ¡encima va a sobrevivirle! ${ }^{19}$

15 La repetición del adverbio natürlich refuerza la actitud aparentemente científica del padre. Compárese en este sentido la frase más arriba citada: "Natürlich würde sich niemand mit solchen Studien beschäftigen".

${ }^{16}$ Ehrich-Haefeli habla de risa irónica (EHRICH-HAEFELI 1990: 248).

${ }^{17}$ La descripción de Odradek, desde su risa sin pulmones que suena coma hojas secas hasta la visión del trozo de madera, es un ejemplo paradigmático de la técnica de negación de Kafka. Al respecto vid. SPRENGEL 2004.

${ }^{18}$ Una corroboración indirecta de la plasticidad del texto de Kafka la proporciona el trabajo del fotógrafo canadiense Jeff WALL que lleva por título “Odradek- Táboritská 8, Praue 18 July 1994”. En el hueco de la escalera de una humilde casa praguense se ve a Odradek y una chica (¿una nieta del Hausvater?) baja por la escalera.

${ }^{19}$ Hillmann también repara en lo superfluo de la partícula auch y según él indica que ha habido un dolor o enfado acumulado que no se ha expresado (crf. HiLlmanN 1967: 203). En mi opi- 
A un nivel más explicito, el origen del disgusto del padre hay que buscarlo en él mismo y su reduccionista visión de la existencia. El padre de familia ha deducido la inmortalidad de Odradek a partir de su propia concepción de la vida, tan rígida como el tono apodíctico e incontestable con el que la articula: "Alles, was stirbt, hat vorher eine Art Ziel, eine Art Tätigkeit gehabt und daran hat es sich zerrieben; das trifft bei Odradek nicht zu". Para el padre, la vida es actividad dirigida hacia un objetivo, es rendimiento y desgaste, la existencia está regida por una finalidad racional y, de hecho, que Odradek no tenga esta existencia lo desacredita a los ojos del padre, como se infiere de la afirmación según la cual Odradek no es peligroso ("Er schadet ja offenbar niemandem"). Y que justamente alguien o algo que se escapa al modelo teleológico, este alguien o algo que está más allá de la utilidad y del desgaste, esta presencia inofensiva, caprichosa o incluso ociosa disfrute de una robustez que no conoce la muerte (o al menos el padre no la presenciará) desmorona anímicamente al padre.

Odradek, dice Hillmann, es una figura de contraste (Hillmann 1967). Y no le falta razón, porque la oscuridad de Odradek ilumina la rigidez de la posición del padre y sus estrategias de disimulo. Sin embargo, creo que aquí es importante distinguir entre el nivel de lucidez que puede alcanzar el lector que, como observador u oidor, reconstruye este contraste y el nivel en el que Kafka deja al padre de familia que es el nivel de un dolor aún no plenamente reconocido: "eine fast schmerzliche Vorstellung". Al final de Die Sorge, queda establecido, pues, un nexo entre la otredad de Odradek y la resistencia a la verbalización de un dolor y, por tanto, se abre una vía de acceso a la extraña criatura que forzosamente tiene que pasar por la asunción de dicho dolor ${ }^{20}$.

\section{Odradek y la extrañeza de las cosas}

En los últimos años, en el seno de la llamada Kulturwissenschaft y a raíz del creciente interés por la cultura material y la teoría de los objetos, la breve narración de Kafka ha cobrado un nuevo protagonismo. Odradek ha dejado de ser una cosa extraña, una incógnita a resolver, para convertirse en una suerte de delegado de todas las cosas y su inherente extrañeza. Con las cosas, dice Harmut Böhme, en su estudio Fetischismus und Kultur nos ocurre lo mismo que a San Agustín con el tiempo: mientras no nos preguntamos qué son, lo sabemos, pero en cuanto inten-

nión, esta partícula subraya el rechazo que el padre siente por Odradek y que ya ha sido tematizado en este trabajo.

${ }^{20}$ Ésta es la vía que implícitamente toman lecturas que, sin detenerse en desbrozar el discurso del padre, entienden que Odradek es parte de aquel. Es el caso de Walter Benjamin quien vio en Odradek una "configuración del olvido" (BENJAMIN [1934] 1988) o del mucho más reciente comentario de Slavoj Žižek que, partiendo de Lacan, considera que Odradek es una encarnación del goce y, por lo tanto, aquello "que no podemos alcanzar nunca, obtener, y aquello de lo que no podremos nunca desprendernos" (ŽıŽEK 2006: 171). 
tamos averiguar su ser, devienen extrañas (Böhme 2006: 35) Por su parte, Peter Geimer dice: "Was mich am Dasein der Gegenstände interessiert, ist ja gerade ihr lakonisches Herumstehen, ihre Stummheit, ihre erhabene Indiferenz. Gegenstände sind äußerst diskrete Wesen" (Geimer 2003: 209) y, si se observa, lo que Geimer dice que le interesa de las cosas en general coincide en gran medida con la imagen de Odradek en particular. Böhme confía en poder aportar los fundamentos para un teoría de los objetos que no adolezca de la carencia que él advierte en la investigación sobre las cosas ya realizada desde la filosofía de cuño fenomenológico, la psicología o la etnología, a saber: que en la atención a las cosas, el centro de interés haya sido el sujeto y no el objeto o el espacio de intersección entre sujeto y objeto (Böhme 2006: 35). Esta voluntad de mirar las cosas desde el lado del objeto claramente redunda en una enfatización de su extrañeza, de su otredad de la cual es muy difícil dar razón sin recurrir a antropomorfismos y aunque es un desideratum compartido el evitarlos se reconoce que es prácticamente imposible ${ }^{21}$. Existe, pues, un deseo de articular una teoría que dé espacio a esta suerte de vida entrecomillada de las cosas que se desarrolla con independencia de los humanos y este deseo convive con la consciencia de que este discurso si no se sirve de modos de hablar metafóricos o directamente literarios ${ }^{22}$ rápidamente enmudece.

Odradek, esta existencia literaria, sirve a Geimer para hablar de algo tan evidente como de que las cosas se mantienen en su lugar aún cuando nosotros no estamos. Este hecho cotidiano en el que no reparamos -no nos detenemos en pensar, por ejemplo, si la lámpara de nuestra mesa escritorio continúa allí mientras nos dirigimos al trabajo- conlleva, en el límite, el saber de nuestra muerte y, en este sentido, Odradek ofrece la imagen plástica perfecta:

Odradeks Stärke ist seine Autonomie, vor allem aber die merkwürdige Dauer, die er zu besitzen scheint [...] Auch diese Eigenschaft der Objekte ist schwer zu begreifen. Ihre Dauer ist kein "Überleben" - sie haben ja nie ein "Leben" gehabt -, sondern ein stummes, scheinbar endloses Verharren. Die Dinge sind zerstörbar, man kann sie zerkleinern, zermahlen und in Stücke zerlegen, aber sie "sterben" nicht (Geimer 2003: 220).

También Böhme parte de la consideración que nuestra relación con las cosas es una relación de profunda dependencia de la que, no obstante, no somos conscientes. Las cosas nos sirven; nosotros vivimos inmersos en nuestras ocupaciones, haciendo realidad nuestros objetivos con la discreta obediencia de las cosas. Tácitamente, nos comportamos como soberanos en el reino de las cosas y solo fantasías en las que interviene la animación de las cosas -una revolución de los objetos, por ejemplo, que puede ser tan pasiva como la de Bartleby, las cosas renitentes preferirían no

21 "Der Vorsatz, hier auf Antropomorphismen zu verzichten, ist berechtigt, zugleich aber kaum einzuhalten. Das Reden über Dinge zwingt immer wieder zu metaphorischen Sprechweisen." (GEIMER 2003: 211).

22 “Über die Dinge nicht-literarisch zu schreiben ist fast unmöglich” (BöHME 2005: 56). 
hacer nuestros encargos- nos pueden ofrecer la ocasión para tomar consciencia de nuestro nexo con la cosas. La fantasía de que los objetos se animan, cobran vida, y el desasosiego que para nosotros, sujetos, se deriva de esta fantasía, Kafka la desarrolla hasta sus últimas consecuencias con Odradek y, según Böhme, estaría confrontándonos con la enorme distancia que siempre nos separa de las cosas -Odradek sólo sería un exponente-: por más que nos acerquemos a ellas, las cosas son puro rechazo, se retraen en sí mismas, son un secreto. Y esta inaccesibilidad de las cosas, que nos seduce (tenemos ganas de hablarles) y que nos las hace aparecer máximamente animadas (las imaginamos realizando una suerte de movimiento de retracción) es la que finalmente nos confronta con nuestra realidad. Porque la animación de las cosas, su movimiento de retirada es hacia un universo donde no hay muerte y cuyo paso es para nosotros infranqueable. Por eso cualquier relación que intentemos mantener con las cosas termina confrontándonos con nosotros mismos, desemboca en "preocupación" (Sorge) por nuestra existencia ante la inmutabilidad de las cosas que actúan como memento mori (Böhme 2006: 43-44)

Pero la animación de Odradek o más bien su hibridez -en parte objeto, en parte sujeto- tiene para Böhme otra lectura. Siguiendo la estela de la llamada antropología simétrica de Bruno Latour, dice: "Die Menschen sind nicht mehr unter sich. Daß heisst auch: Odradek ist unter uns, wir haben es nur noch nicht verstanden. Es ist irgerndwie unheimlich" (Böhme 2006: 82). Si por una parte, las cosas nos recuerdan que estamos solos con nuestra intransferible muerte, por otra parte, según Böhme (con Latour) es preciso reconocer que una buena parte de las acciones humanas más cotidianas son el resultado de la cooperación entre sujetos y objetos, resultado de una hibridez entre lo humano y lo no humano. Ahí están las ilustraciones de esta teoría que han hecho fortuna como son la flexible pértiga del atleta o los resaltos en las vías públicas que obligan a los conductores a circular más despacio, ejemplos de objetos que nos permiten ver que actuar no es solo una capacidad humana sino la capacidad de "una reunión de actantes" y que partes de la estructura social de las sociedades modernas han sido históricamente transformadas en estructuras técnicas en las que cooperamos sin apenas tener consciencia de este trabajo conjunto. El reconocimiento de que no estamos solos, de que los humanos no lo hacemos todo en solitario, la concesión a las cosas de un espacio de articulación dentro del discurso humano debe redundar, dice Böhme (con Latour) en un aumento de democracia (Böhme 2006: 82). Dejando ahora aparte esta más que dudosa e intrincada cuestión y pensando en nuestro Odradek, cabe resaltar que esta presentación del entramado social en el que una parte de las acciones humanas son comandadas por los objetos es, a fin de cuentas, la visión de un mundo ordenado en el que por lo general las cosas (y con ellas los humanos) hacen lo que tienen que hacer. Y al convertir a Odradek en icono de esta visión de mundo, se desactiva su extrañeza, su potencial subversivo (de contraste) se disuelve en la norma.

Aparte de la misión de representar la genérica extrañeza de las cosas, sobre la historia de Odradek ha recaído otra responsabilidad de envergadura: la de ser un 
metatexto, una suerte de comentario literario sobre la presencia de cosas en la literatura $^{23}$. Los textos literarios son especialmente aptos para representar la extrañeza que causa un mundo material que parece tener una lógica propia y la vida que alcanzan las cosas en terreno literario cabe leerla como sinónima de la pregunta por todo lo que se resiste a la determinación conceptual, en palabras de Kimmich: "Dinge lösen daher Befremden, aber auch Angst, Ekel, Sorge, manchmal auch Belustigung oder Schwindel aus" (Kimmich 2007: 75). Y es en este sentido que Odradek cumple su cometido; su origen y su futuro son inciertos, carece de sentido y, sin embargo, está ahí como un mensajero:

Er [Odradek] ist wie ein Bote aus einer Welt, die neben dem, was die Menschen erfassen können besteht [...] Er/Es ist ein Bewohner unserer Welt und macht uns damit deutlich, dass diese nicht abhängig davon existiert, ob wir sie verstehen oder nicht. [...] Diesen Hinweis auf die Unlesbarkeit der Welt scheinen viele Dinge zu geben, die durch die Texte der modernen Literatur geistern (Kimmich 2007:80).

Odradek como presencia que excede nuestra capacidad de comprensión, como representante de la extrañeza de las cosas actuaría como recordatorio de que no todo lo que existe forma parte de nuestro orden o de orden alguno.

\section{Conclusión}

Convertido en el vicario de todas las cosas, Odradek está involucrado en un discurso nebuloso. Por una parte, la insistencia en el ser impenetrable de las cosas, en su rechazo, y la evidencia de que no conseguimos hablar de ellas si no es acudiendo a un lenguaje nutrido de metáforas e imágenes antropomórficas nos sitúa ante una pregunta que prácticamente cae por su propio peso: ¿por qué no dejar, pues, que la literatura siga fabulando este mundo de las cosas que nos está vedado y olvidar ciertas aproximaciones teóricas que aunque se presentan humildemente ${ }^{24}$ no logran disimular su vacuidad? Por otra parte, el poner énfasis en el misterio de las cosas ocurre en paralelo con la propagación de una nueva modestia o conciencia de finitud: se propugna la "confraternización" con las cosas o se nos recuerda que la existencia del mundo no depende de que los humanos la entendamos. Da la impresión de que, en nuestros días, la lectura de Die Sorge des Hausvaters está pasando por sus horas más bajas y tal vez habrá que dejar pasar el tiempo para que Odradek deje de ser un comodín y recupere plenamente su existencia de ficción literaria que, en su caso, equivale a inagotable provocación ${ }^{25}$.

${ }^{23}$ Esta es la propuesta de Dorothee KIMMICH recogida en el número dedicado a Fremde Dinge de la Zeitschrift für Kulturwissenschaften (2007).

${ }^{24}$ Geimer dice que lo que él hace es "Halbstarkenmusik" (GEIMER 2003: 209-211).

${ }^{25}$ Quizás comparable a la de Bartleby, el humano cosificado, en el relato de Melville. 


\section{Referencias bibliográficas}

Alt, P-A., Franz Kafka. Der ewige Sohn. Eine Biographie. München: Verlag C.H. Beck 2005. BeIBNER, F., Der Erzähler Franz Kafka. Frankfurt am Main: Suhrkamp 1983.

BenJAmin,W., Angelus Novus. Ausgewählte Schriften 2. Frankfurt am Main: Suhrkamp 1988. BINDER, H., Kafka Kommentar zu sätmlichen Erzählungen. München: Winkler Verlag 1975.

BöHME, H., Fetischismus und Kultur. Eine andere Theorie der Moderne. Reinbeck bei Hamburg: Rowohlt Taschenbuch Verlag 2006.

Borges, J. L., El Libro de los seres imaginarios. Con la colaboración de Margarita Guerrero. Barcelona: Destino 2007.

Ehrich-HAEFEli,V., «Bewegungsenergien in Psyche und Text. Zu Kaflas ,Odradek'», Zeitschrift für deutsche Philologie 109 (1990), 238-253.

GEIMER, P., «Theorie der Gegenstände». «Die Menschen sind nicht meher unter sich», en: Huber, J. (Hg.), Person/Schauplatz. Zürich: Voldemeer 2003, 209-222.

HillmanN, H., «Das Sorgenkind Odradek», Zeitschrift für deutsche Philologie 86 (1967), 197-210.

KafKA, F., Franz Kafka. Drucke zu Lebzeiten, en Kittler, W., Koch, H.-G. y NeumanN, G. (eds.), Frankfurt am Main: Fischer TaschenbuchVerlag: 2002.

KIMMICH, D., «Mit blasiert eleganter Frivolität. Von der Begegnung mit fremden Dingen», Zeitschrift für Kulturwissenschaften (ZfK)1(2007), 73-83.

LAtour, B., Nunca fuimos modernos. Ensayo de antropología simétrica. Buenos Aires: Siglo XXI Editores 2007.

MiLnER, J.-C., «Odradek, la bobine de scandale», Elucidation 10 (2004), 93-96.

SABE, G., «Die Sorge des Hausvaters», en: Müller, M. (Hg.), Interpretationen. Franz Kafka. Romane und Erzählungen. Stuttgart: Reclam 2003, 313-323.

SABE, G., «Die Sorge des Lesers. Zu Kafkas Erzählung Die Sorge des Hausvaters», Poetica: Zeitschrift für Sprach- und Literaturwissenschaft 10 (1978), 262-284.

SPRENGEL,P., Geschichte der deutschsprachigen Literatur 1900-1018. Von der Jahrhundertwende bis zum Ende des Ersten Weltkriegs. München: Verlag C.H. Beck 2004.

STAHL, A., «Konfusion oder Absicht? Zur Interpretation von Kafkas Erzählung "Die Sorge des Hausvaters"», Saarbrücker Beiträge zur Ästhetik (1966), 67-78.

STIFTER, A., Der Nachsommer. München: dtv 2005.

WAgenbaCH, K., Franz Kafka. Bilder aus seinem Leben. Berlin: Verlag Klaus Wagenbach 1983.

ŽIŽEK, S., Visión de paralaje. Buenos Aires: Fondo de Cultura Económica 2006. 